\title{
Conocimientos culturales y de trivia en dos grupos universitarios de Chile
}

\section{NELSON A. VARGAS C. ${ }^{1}$, DANTE PINOCHET T. ${ }^{2}$, PAULA JUÁREZ E. ${ }^{3}$}

Background: Culture is defined by the Webster's dictionary as acquaintance with and taste in fine arts, humanities, and broad aspects of science as distinguished from vocational and technical skills. Aim: To assess the general cultural knowledge of university students. Material and Methods: A test containing 58 questions about art, national and universal literature, national and universal history, mythology, science and trivial national issues was designed and applied to 251 medical students in Santiago (149 from first year and 86 from fifth year, Universidad de Chile) and 138 agronomy students in Valdivia (61 from first year and 77 from fifth year, Universidad Austral de Chile). Results: All students answered the test. Medical students from first and fifth year omitted 19 and 15\% of questions respectively. The figures for first and fifth year agronomy students were $23 \%$ each. The percentage of correct answers among first and fifth year medical students was 50 and 59\% respectively. The figures for first and fifth year agronomy students were 39 and 44\% respectively. The questions with higher rates of correct answers were those about trivial issues. Conclusions: There was a high rate of omissions and wrong answers about general cultural issues among university students particularly in national cultural subjects.

(Rev Med Chile 2010; 138: 289-294).

Key words: Cultural characteristics; Students, medical; Universities.

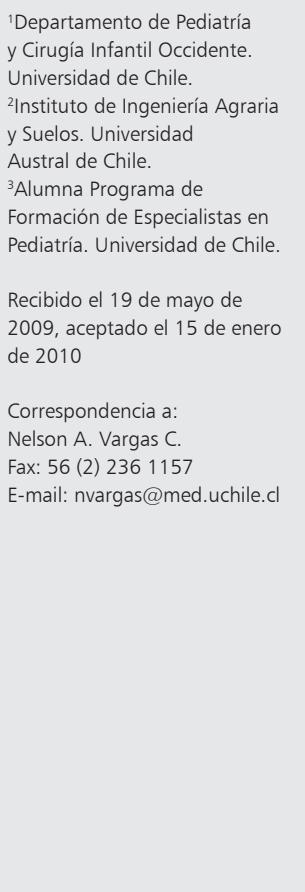

$\mathrm{C}$ ultura es definida por la Real Academia Española como el "conjunto de conocimientos que permiten a una persona desarrollar un juicio crítico" $\mathrm{y}$ se podría postular que incluye conocimientos, conductas y actitudes mantenidos en el bagaje de una comunidad. Se evidenciaría -parcialmente- por conocimientos que permiten entender, comunicarse y apreciar los valores, símbolos y expresiones humanas.

Vecino a ese término, pero diferente, en el lenguaje coloquial se usa el de "trivia", de trivial (del latín, trivialis), algo vulgarizado, común y sabido por todos y, en otra acepción, "que no sobresale de lo ordinario y común, que carece de toda importancia y novedad"2. Coloquialmente, el término trivia alude a juegos de preguntas y respuestas sobre temas actuales. La cultura sería más permanente e importante que la trivia para el desarrollo humano integral.

La información técnica es una tercera categoría de conocimientos -imprescindible para el desempeño profesional- distinta de la cultura y del saber trivial.

El escenario social actual, dominado por medios masivos de comunicación, brinda poco tiempo para desarrollar potencialidades culturales o expresiones espirituales, pese a la gran conectividad prevalente. El mundo profesional, expansivo, competitivo y absorbente, requiere gran número de competencias que los estudiantes universitarios se ven obligados a incorporar, reduciendo su posibilidad de adquirir cultura; pese a que las univer- 
sidades intentan entregar una formación integral. Surge, entonces, un conflicto entre dedicar tiempo curricular a lo cultural o a crear competencias para el mundo técnico y nacen dudas acerca del logro de la formación integral.

En este contexto, el propósito de este estudio fue cuantificar conocimientos escogidos, de cultura (general y nacional) y trivialidades, en dos grupos universitarios de distintos lugares (Santiago y Valdivia) y carreras (agronomía y medicina). Los objetivos específicos fueron a) cuantificar el número y proporción de respuestas omitidas y correctas en una prueba de selección múltiple sobre áreas culturales (generales y nacionales) y triviales y b) precisar las diferencias en conocimientos.

\section{Material y Método}

El año 2008 se aplicó una encuesta ideada por los autores, anónima y voluntaria, de 58 preguntas con 5 alternativas (una correcta, sin formulación negativa): 44 de cultura y 14 de temas triviales, frecuentes en medios de comunicación. En el total, 23 correspondían a temas chilenos (17 de cultura; 6 , de trivia). Se incluyó más preguntas de cultura para poder cubrir un mayor espectro de temas, como arte $(\mathrm{n}=5)$; literatura universal ( $\mathrm{n}$ $=5)$ y nacional $(\mathrm{n}=5)$; historia universal $(\mathrm{n}=5)$ y nacional $(n=5)$; mitología $(n=5)$; personajes nacionales y extranjeros $(n=6)$; ciencia $(n=5)$ y expresiones en otras lenguas y geografía $(n=2)$. Las preguntas y temas, arbitrariamente decididos, cuidaron que ambos se ordenaran al azar. La encuesta se probó en 12 personas -excluidas en la segunda aplicación- para evaluar comprensión y tiempo invertido.

En marzo-abril se aplicó en la carrera de Medicina de la Universidad de Chile (Santiago), a 251 personas de 2 grupos: 149 estudiantes de primero y 86 de quinto año. En octubre-noviembre se aplicó en la Facultad de Ciencias Agrarias, carrera de Agronomía, de la Universidad Austral de Chile (Valdivia), a 138 personas: todo el primer año (n $=61)$ y el quinto o más $(\mathrm{n}=77)$. Ningún alumno rehusó participar.

Se escogieron esas carreras, lugares y cursos por la facilidad para ejecutar el trabajo, por ser dos de los autores académicos de esas carreras, y se trabajó en regiones para explorar, con un solo esfuerzo, más variables.

Los conocimientos se estudiaron calculando la omisión de respuesta (en sí, una forma de contestar) y los aciertos. Se comparó las carreras, los cursos dentro y entre ellas y el comportamiento de las preguntas de cultura mundial, nacional y de trivialidades.

Los datos fueron procesados en una planilla Excel v. 5,0. Las diferencias entre promedios se evaluaron calculando la t de Student, usando el programa GraphPad Prism, versión 4,0. Las diferencias entre porcentajes se estudiaron con el cálculo de $\mathrm{Z}$ y error alfa de 0,05\%.

\section{Resultados}

Al comparar primer y quinto año de cada carrera, la proporción de mujeres disminuyó en agronomía, desde 47,5\% ( $\mathrm{n}=29)$, en primer año, a $37,7 \%(n=20)$, en quinto. Lo inverso ocurrió en medicina, donde aumentó significativamente $(\mathrm{p}<0,05)$ de $36,9 \%(\mathrm{n}=55)$, en primero, a $51,2 \%$ $(\mathrm{n}=44)$, en quinto.

Los grados de omisión y respuesta en los cinco grupos estudiados se presentan en las Tablas 1 y 2 .

\section{Omisión de respuesta (no contestadas)}

Fue alta en todos los grupos, aunque también hubo encuestas completas. La encuesta con omisión mayor estuvo en ambos primeros años (44, en primero de agronomía, y 43, en primero de medicina).

Omisión bajo 10\% (correspondería a preguntas sobre temas conocidos): Osciló entre 13,8\% y $32,8 \%$ de las 58 preguntas. Quinto de medicina tuvo la mejor cifra de omisión baja, al comparar con los otros tres grupos de estudiantes.

Omisión sobre 50\% (temas menos conocidos): Fluctuó entre $13,8 \%$ y $36,2 \%$ de las 58 preguntas (Tabla 2). El quinto de medicina tuvo frecuencia significativamente menor que el quinto de agronomía de preguntas con omisión sobre $50 \%$.

Omisión alta (sobre 70\%, temas desconocidos). Sólo afectó a preguntas de cultura.

Agronomía. En primer año fueron 6 preguntas (4, cultura nacional). Aludían a "Gran Señor y Rajadiablos”, Paul Klee y Juan Francisco González, la cantinera Sargento Candelaria, Manso de Velasco $\mathrm{y}$ las vestales. En quinto año fueron 11 y consultaban por González, Klee, Rebeca Matte y Fidias, Manso de Velasco, "Gran Señor y Rajadiablos", Karl Popper, la batalla de Gránico, "Lilí Marlene", 
Tabla 1. Grados de omisión y respuesta en las 58 preguntas

\begin{tabular}{|c|c|c|c|c|}
\hline & \multicolumn{2}{|c|}{$\begin{array}{c}\text { Agronomía } \\
\text { Universidad Austral }\end{array}$} & \multicolumn{2}{|c|}{$\begin{array}{c}\text { Medicina } \\
\text { Universidadde Chile }\end{array}$} \\
\hline & $\mathbf{I}$ & $\mathbf{v}$ & $\mathbf{I}$ & $\mathbf{v}$ \\
\hline \multicolumn{5}{|l|}{ Omitidas } \\
\hline Promedio & 22,6 & 23,2 & 19,4 & 14,7 \\
\hline Mediana & 26,0 & 24,0 & 21,0 & 14,0 \\
\hline Respuestas en encuesta con más omisión & 14 & 17 & 15 & 21 \\
\hline \multicolumn{5}{|l|}{ Respondidas } \\
\hline Promedio & 35,4 & 34,8 & 38,6 & 43,3 \\
\hline Mediana & 32,0 & 34,0 & 37,0 & 44,0 \\
\hline
\end{tabular}

Tabla 2. Distribución de las 58 preguntas según porcentaje de omisión en los cuatro grupos encuestados

\begin{tabular}{|c|c|c|c|c|c|c|c|c|}
\hline \multirow{3}{*}{$\%$ de omisión } & \multicolumn{8}{|c|}{ Número de preguntas } \\
\hline & \multicolumn{4}{|c|}{ Agronomía. Universidad Austral } & \multicolumn{4}{|c|}{ Medicina. Universidad de Chile } \\
\hline & $\mathbf{I}$ & $\%$ & $\mathbf{v}$ & $\%$ & $\mathbf{I}$ & $\%$ & $\mathbf{v}$ & $\%$ \\
\hline$<10$ & 8 & 13,8 & 10 & 17,3 & 11 & 19,0 & 19 & $32,8^{*}$ \\
\hline $10-29$ & 17 & 29,3 & 14 & 24,1 & 19 & 32,8 & 17 & 29,3 \\
\hline $30-49$ & 12 & 20,7 & 13 & 22,4 & 13 & 22,4 & 12 & 20,7 \\
\hline 50 y más & 21 & 36,2 & 21 & 36,2 & 15 & 25,8 & 10 & $17,2^{* *}$ \\
\hline Total & 58 & 100,0 & 58 & 100,0 & 58 & 100,0 & 58 & 100,0 \\
\hline
\end{tabular}

*Diferencias significativas $(p<0,05)$ entre quinto de medicina y los otros tres grupos. ${ }^{*}$ Diferencia significativa al comparar ambos quintos años.

la Sargento Candelaria y las vestales ( 5 , de cultura nacional).

Medicina. En primer año fueron 6 preguntas. Aludían a: "Lilí Marlene", "Gran Señor y Rajadiablos", la Sargento Candelaria, González, Matte y Manso de Velasco (5 son de la historia y vida nacionales). En quinto año fueron 3. Aludían a: "Lilí Marlene”, “Gran Señor y Rajadiablos” y González (2 son nacionales).

\section{Respuestas correctas (Tabla 3)}

Acierto sobre $60 \%$. Se escogió este porcentaje como punto de corte porque pensamos que es fácil de evocar y recordar y correspondería a un tema conocido por los encuestados. Treinta y cuatro de las 58 preguntas alcanzaron este acierto alto, significativamente más frecuente $(\mathrm{p}<0,01)$ en la trivia $(92,9 \%, \mathrm{n}=13)$ que en la cultura $(47,7 \%, \mathrm{n}=21)$.

En esas mismas 34 preguntas, 15 ( 8 de la vida nacional) alcanzaron ese nivel en todos los grupos. Se estimó que un nivel de respuesta correcta sobre
$60 \%$, en todos los grupos, permite calificar al tema como "universalmente conocido". Esto ocurrió en 7 preguntas de trivia ( 5 , nacional) y 8 , de cultura. Este nivel de acierto fue significativamente mejor $(\mathrm{p}<0,05)$ en la trivia que en la cultura.

Lo trivial más acertado fue nacional (Borghi, Bolocco, Conserva, Salas y Pamela Díaz), con sólo 2 preguntas de trivia internacional (Potter y Spears).

En las 8 de cultura más conocidas se ubicaron 3 nacionales (Lillo, premios Nobel de Chile y Bello).

Agronomía. Primer año. 16 preguntas tuvieron más de $60 \%$ de acierto (8, de cultura; 8 , triviales. Destacaron Don Quijote, Spears; Potter; Salas; genoma humano y Conserva). Acierto decreciente tuvieron las relacionadas con Borghi, Díaz; Bello, premios Nobel nacionales; Bolocco; Shakespeare; Lillo; Freud; Neptuno y Shakira. En quinto año fueron 18 preguntas (8 de cultura; 10 triviales). Lideraron: Potter, Salas, Don Quijote; Spears, Borghi; Conserva; Bolocco y el hongo Penicillium; 
Tabla 3. Las 34 más acertadas: Preguntas con acierto sobre $60 \%$

\begin{tabular}{|c|c|c|c|c|}
\hline \multirow[t]{2}{*}{ Tema de la pregunta } & \multicolumn{2}{|c|}{ Agronomía } & \multicolumn{2}{|c|}{ Medicina } \\
\hline & $\mathbf{I}$ & $\mathbf{v}$ & $\mathbf{I}$ & $\mathbf{v}$ \\
\hline Britney Spears & 96,7 & 96,1 & 98,7 & 95,3 \\
\hline Don Quijote & 96,7 & 96,1 & 99,3 & 98,8 \\
\hline Harry Potter & 93,4 & 97,4 & 99,3 & 97,7 \\
\hline Marcelo Salas & 91,8 & 96,1 & 96,0 & 93,0 \\
\hline Claudia Conserva & 90,2 & 93,5 & 85,9 & 94,2 \\
\hline Genoma humano & 90,2 & 83,1 & 84,6 & 65,1 \\
\hline Borgui & 82,0 & 94,8 & 86,6 & 91,9 \\
\hline Pamela Díaz & 82,0 & 88,3 & 82,6 & 95,3 \\
\hline Cecilia Bolocco & 77,0 & 92,2 & 75,8 & 81,4 \\
\hline Chilenos Premio Nobel & 78,7 & 87,0 & 92,6 & 95,3 \\
\hline Shakespeare & 75,4 & 83,1 & 89,9 & 91,9 \\
\hline Teniente Bello & 78,7 & 62,3 & 79,9 & 77,9 \\
\hline Freíd & 70,5 & 74,0 & 98,0 & 97,7 \\
\hline Baldomero Lillo & 72,1 & 61,0 & 90,6 & 79,1 \\
\hline Shakira & 60,7 & 70,1 & 65,1 & 80,2 \\
\hline Penicillium & & 90,9 & 63,8 & 90,7 \\
\hline Raquel Argandoña & & 77,9 & 65,1 & 82,6 \\
\hline Neptuno & 60,7 & & 75,2 & 74,4 \\
\hline Esposos Curie & & & 93,3 & 84,9 \\
\hline Joaquín Sabina & & 64,9 & & 68,6 \\
\hline Poetas chilenos sin Nobel & & & 61,7 & 69,8 \\
\hline Virgo & & & 74,5 & 77,9 \\
\hline Ritmos circadianos & & & & 97,7 \\
\hline Expresión usual extranjera & & & & 86,0 \\
\hline Bielsa & & & & 74,4 \\
\hline Minotauro & & & 75,8 & 79,1 \\
\hline Nefertiti & & & & 77,9 \\
\hline Mar del Norte & & & & 65,1 \\
\hline Google & & & & 77,9 \\
\hline \multicolumn{5}{|l|}{ Los Miserables } \\
\hline \multicolumn{5}{|l|}{ Rodin } \\
\hline \multicolumn{5}{|l|}{ Lili Marlene } \\
\hline \multicolumn{5}{|l|}{ Nepal } \\
\hline Política chilena siglo XX & & & & 64,0 \\
\hline $\mathrm{N}$ & 16 & 18 & 22 & 30 \\
\hline
\end{tabular}

seguidas por las de Díaz; premios Nobel; Shakespeare; genoma humano; Argandoña; Freud; Shakira; Sabina; Bello y Lillo.

Medicina. Primer año, 22 preguntas tuvieron más de $60 \%$ de acierto (12 de cultura; 10 triviales). Destacaron Don Quijote y Potter, seguidos por Spears; Freud y Salas, los esposos Curie y los premios Nobel nacionales (séptimo lugar). En las 7 mejor respondidas, 3 fueron de trivia y 4 de cultura (sólo una nacional). En quinto año fueron 30 preguntas: 13 de trivia ( 7 , nacional) y 17 de cultura. Las 7 mejores fueron: Don Quijote, ritmos circadianos, Potter, Freud, premios Nobel nacionales, Spears y Díaz (4 de cultura, sólo una de cultura nacional).

La Tabla 4 compara los promedios de correctas: El más alto estuvo en quinto de medicina y el más bajo, en primero de agronomía. En ambas carreras el promedio fue mejor en quinto año que en su respectivo primero ( $\mathrm{p}$ : 0,0095, en agronomía; $\mathrm{p}<0,0001$, medicina). Primero de medicina tuvo promedio mejor que primero de agronomía $(\mathrm{p}<0,0001)$ y quinto de medicina, mejor que quinto de agronomía $(\mathrm{p}<0,001)$.

Acierto bajo 20\% (Tabla 5) y 10\% (temas desconocidos). Cinco temas -todos de cultura, 1 de cultura nacional- estuvieron bajo $20 \%$ de acierto en todos los grupos: la batalla de Gránico, "Os Lusíadas”, Manso de Velasco, la Candelaria y las vestales.

Agronomía. Primer año. Las 6 preguntas con acierto bajo $10 \%$ fueron todas de cultura (3, nacional): "Gran Señor y Rajadiablos", Klee, "Los Miserables", Manso de Velasco, "Os Lusíadas" y la Candelaria. Este curso tuvo 22 preguntas bajo $20 \%$ de acierto (Tabla 5). Quinto año. Las 8 con acierto bajo 10\% fueron: "Gran Señor y Rajadiablos"; Popper; Klee; Manso de Velasco; "Os Lusíadas"; la Candelaria; "Adiós al Séptimo de Línea" y las vestales. Todas son de cultura (4, nacional). El quinto año tuvo 16 preguntas bajo $20 \%$ de acierto.

Medicina. Primer año. Las 5 preguntas con acierto bajo $10 \%$ fueron de cultura: 
Tabla 4. Preguntas correctas: Promedio, desviación estándar (DE) y porcentaje en el total de preguntas

\begin{tabular}{|cccc|}
\hline & Promedio & DE & \% en las 58 preguntas \\
Agronomía & & & \\
I & 22,6 & 6,8 & 39,0 \\
V & 25,4 & 5,7 & 43,8 \\
Medicina & & & \\
I & 28,9 & 6,1 & 49,8 \\
V & 34,5 & 7,4 & 59,4 \\
\hline
\end{tabular}

Diferencias significativas: Agronomía. Primero versus quinto: $p<0,0095$ Medicina. Primero versus quinto: $p<0,0001$. Entre ambas carreras. Primero vs primero: $p<0,0001$; Quinto vs quinto: 0,001.

Tabla 5. Las 23 menos acertadas: Preguntas con acierto bajo $20 \%$

\begin{tabular}{|lrrrr|}
\hline Tema de la pregunta & \multicolumn{2}{c}{ Agronomía } & \multicolumn{2}{c|}{ Medicina } \\
& I & V & I & V \\
\hline Batalla de Gránico & 13,1 & 11,7 & 14,1 & 18,6 \\
\hline Manso de Velasco & 8,2 & 6,5 & 14,8 & 14,0 \\
\hline Os Lusiadas & 8,2 & 9,1 & 8,1 & 15,1 \\
\hline Sargento Candelaria & 9,8 & 1,3 & 7,4 & 16,3 \\
\hline Vestales & 14,8 & 9,1 & 10,1 & \\
\hline Juan F. González & 11,5 & 10,4 & 6,0 & 17,4 \\
\hline Séptimo de Línea & 11,5 & 9,1 & 14,8 & 17,4 \\
\hline Gran Señor y Rajadiablos & 4,9 & 5,2 & 6,0 & 8,1 \\
\hline Karl Popper & 18,0 & 6,5 & & 17,4 \\
\hline Rebeca Matte & 14,8 & 11,7 & 15,4 & \\
\hline Lili Marlene & 13,1 & & 4,7 & 16,3 \\
\hline Klee & 8,2 & 2,6 & 10,7 & \\
\hline Bizancio & 13,1 & 19,5 & & \\
\hline Fidias & 13,1 & 14,3 & & \\
\hline Francisco Bilbao & 18,0 & 19,5 & & \\
\hline Rodin & 16,4 & 16,9 & & \\
\hline Estrogonoff & 11,5 & & 10,7 & \\
\hline José M. Balmaceda & 16,4 & 13,0 & & \\
\hline Esplendor cultura griega & & & & \\
\hline República Portaliana & 16,4 & & & \\
\hline Ritmos circadianos & 13,1 & & & \\
\hline Los Miserables & 8,2 & & & \\
\hline Pedro Aznar & 11,5 & & & \\
\hline N & 22 & 16 & 12 & \\
\hline
\end{tabular}

"Gran Señor y Rajadiablos"; González; "Lilí Marlene", "Os Lusíadas" y la Candelaria (2, de cultura nacional). El curso tuvo 12 preguntas bajo $20 \%$ de acierto. Quinto año. Sólo una pregunta (de cultura nacional) tuvo menos de $10 \%$ de correctas y 9 , menos de $20 \%$.

\section{Cultura versus trivia}

Se realizaron tres comparaciones entre las 44 preguntas de cultura y las 14 triviales; todas resultaron favorables a lo trivial.

Primera comparación: Proporción con omisión sobre $30 \%$. Con una excepción, esta sólo afectó -significativamente ( $\mathrm{p}<$ $0,05)$ - a preguntas de cultura, en ambas carreras.

Agronomía. Primer año: 30 preguntas de cultura $(68,2 \%)$ afectadas; mientras en trivialidades fueron sólo $3(21,4 \%)$. Quinto año: 34 de cultura (77,3\%) sin afectar preguntas triviales.

Medicina. Primer año. 25 preguntas de cultura $(56,8 \%)$ afectadas; mientras que en trivialidades sólo fueron 3 (21,4\%). Quinto año: 22 (50\%) de las de cultura, sin afectar la trivialidad.

Segunda comparación. Omisión bajo $10 \%$ (las más contestadas). En ambas carreras la omisión baja fue más frecuente en trivialidad.

Agronomía. Primer año: 8 preguntas: 4 , en cultura $(9,1 \%)$ y 4 , en trivialidades $(28,6 \%)$. Quinto año: 9 preguntas: 3 de cultura $(6,8 \%)$ y $6(42,9 \%)$, en trivialidad.

Ambas diferencias son significativas $(\mathrm{p}<0,05)$.

Medicina. Primer año: 11 preguntas: 8 en cultura $(18,2 \%)$ y $3(21,4 \%)$, en trivialidad. Quinto año: 19 preguntas: 10 en cultura $(22,7 \%)$ y $9(64,3 \%)$ en trivialidad $(\mathrm{p}<0,05)$.

Tercera comparación. Proporción de respuestas correctas. En ambas carreras lo trivial fue siempre fue mejor respondido $(\mathrm{p}<0,05)$.

Agronomía. Primer año, 21 preguntas tuvieron acierto sobre 50\%: 11 de cultura 
(25\%) y 10 de trivialidad (71,4\%). Quinto año: 23 preguntas: 11 de cultura, (25\%) y 12 en trivialidad $(85,7 \%)$.

Medicina. Primer año, 29 preguntas tuvieron más de $50 \%$ de acierto: 17 de cultura $(38,6 \%)$ y 12 $(85,7 \%)$ de trivialidad. Quinto año: 36 preguntas: 23 de cultura (52,3\%) y 13 (92,9\%), en trivialidad.

\section{Discusión}

El trabajo intentó medir conocimientos de cultura, considerada con cierta frecuencia una manifestación de desarrollo, y pudiese ser acusado de pretencioso: quien formula y selecciona temas, preguntas y respuestas asume que cubre cultura y trivialidad en forma adecuada. Esta crítica hipotética no impide hacer el intento.

Los conocimientos de personas o grupos están sujetos a muchas determinantes ambientales, derivadas de la edad, el tipo y extensión de su educación formal, historia, intereses y habilidad personal ${ }^{4}$.

En ocasiones, la diferencia entre trivia y cultura es sutil: algo trivial, si permanece y se incorpora al saber grupal, puede llegar a ser parte de su bagaje, dado que la cultura no es estática. Es posible que la expresión "más perdido que el teniente Bello" haya pasado a la cultura a partir de un uso generalizado, cuando el aviador desapareció.

Esta encuesta intentó obtener una visión aproximada, en grupos universitarios, y hay conclusiones interesantes, útiles para idear una mejoría de la realidad detectada.

Nos parece que los hallazgos centrales del estudio son cuatro:

$1^{\circ}$ Hay un nivel importante de omisión de respuestas. Creemos que la gran omisión puede tener tres orígenes: ignorancia, desinterés o falta de tiempo para responder. En todos los grupos la omisión fue importante, lo que sugiere una falencia importante en el área explorada; peor en la cultura nacional, cuyas 17 preguntas fueron omitidas con frecuencia. La comparación de la omisión alta y baja entre cultura y trivia muestra, sostenidamente, más respuestas en la segunda.

$2^{\circ}$ Muchas preguntas fueron mal contestadas. El desconocimiento mayor se ubica en la cultura, en especial en la cultura nacional. En respuestas correctas, otra vez la cultura -en especial la nacional- aparece en desmedro, con aspectos clásicos (la Sargento Candelaria, "Gran Señor y Rajadiablos”, Juan Francisco González, Rebeca Matte y Manso de Velasco) casi desconocidos. 3o El conocimiento trivial supera al cultural.

$4^{\circ}$ Hay diferencias claras que favorecen a la carrera de medicina, de Santiago.

No tenemos explicación para este último hallazgo aunque, hipotéticamente y sin que lo podamos probar con este estudio, podría explicarse por mejor puntaje de ingreso a la carrera o mayor ingreso económico o mayor acceso a estímulos culturales, al vivir en Santiago.

Las Universidades deben preparar profesionales con alto nivel de competencias. El concepto de competencia -vigente en la educación moderna- implica una relación estrecha, permanente y cambiante del profesional con su medio. No se concibe eficiencia sin la capacidad de incorporar y crear nuevas soluciones en un ambiente velozmente mutable. Las competencias serán mejores si el sujeto conoce el medio en que se va a insertar, incluyendo su cultura y trivialidades.

Nuestros resultados sugieren una debilidad general en lo cultural, más evidente en lo nacional, hecho relevante en un país que pretende ser parte de la globalización, con un bagaje propio, después de 200 años de independencia. Hace 100 años las clases educadas de Chile estaban fuertemente influidas por Francia. Actualmente, la mayor influencia proviene de los Estados Unidos de Norteamérica y el inglés es la segunda lengua de los grupos educados. Esta evolución y el mirar intensamente al exterior pueden explicar, en parte, la debilidad que se insinúa en el conocimiento de nuestra cultura. Cuando el país celebra su bicentenario cabe reflexionar si las Universidades deben recoger este problema.

\section{Referencias}

1. http://buscon.rae.es/draeI/SrvltConsulta?TIPO_BUS= 3\&LEMA=cultura. Consultado el 27 de febrero de 2008.

2. http://buscon.rae.es/draeI/SrvltConsulta?TIPO_BUS= 3\&LEMA=trivial. Consultado el 27 de febrero de 2008.

3. Montiel, E. El nuevo orden simbólico: la diversidad cultural en la era de la globalización. Lit. lingüíst., 2003; no. 14, p. 61-91. ISSN 0716-5811.

4. Ramírez Varela, F. El Mito de la Cultura Juvenil. Ultima décad., Ago 2008, vol.16, no. 28, p. 79-90. ISSN 0718-2236. 